\title{
Simulation-Based Learning: From Learning Theory to Pedagogical Application
}

\author{
Sarah Ross \\ Samford University, sross@samford.edu
}

Follow this and additional works at: https://nsuworks.nova.edu/ijahsp

Part of the Medicine and Health Sciences Commons

\section{Recommended Citation}

Ross S. Simulation-Based Learning: From Learning Theory to Pedagogical Application. The Internet Journal of Allied Health Sciences and Practice. 2021 Oct 01;19(4), Article 15.

This Review Article is brought to you for free and open access by the College of Health Care Sciences at NSUWorks. It has been accepted for inclusion in Internet Journal of Allied Health Sciences and Practice by an authorized editor of NSUWorks. For more information, please contact nsuworks@nova.edu. 


\title{
Simulation-Based Learning: From Learning Theory to Pedagogical Application
}

\begin{abstract}
Simulation is a powerful learning tool, but being powerful requires understanding and incorporating sound educational learning theory and pedagogical practices into the design and implementation. Unfortunately, current research and publication related to simulation show limited evidence of integration of educational theory. While articles may reference learning theories in introductions or literature reviews, there is little evidence of these theories being integrated into the conceptual framework, research, or simulation-based learning event design. The purpose of this article is to highlight four learning theories that are most commonly integrated into simulation-based learning activities and how they can be specifically and practically applied to pedagogical approaches.
\end{abstract}

\section{Author Bio(s)}

Sarah Ross, PT, DPT, GCS, CEEAA, is an Assistant Professor of Physical Therapy at Samford University in Birmingham, Alabama, and a PhD candidate in Mercer University's Tift College of Education in Atlanta, Georgia. She is also a licensed physical therapist in the state of Alabama. 


\section{IJAHSP \\ The Internet Joumnal of Allied Health Sciences and Practice \\ Dedicated to allied health professional practice and education \\ Vol. 19 No. 4 ISSN 1540-580X}

\section{Simulation-Based Learning: From Learning Theory to Pedagogical Application \\ Sarah Ross \\ Samford University \\ United States}

\section{ABSTRACT}

Simulation is a powerful learning tool but being powerful requires understanding and incorporating sound educational learning theory and pedagogical practices into the design and implementation. Unfortunately, current research and publication related to simulation show limited evidence of integration of educational theory. While articles may reference learning theories in introductions or literature reviews, there is little evidence of these theories being integrated into the conceptual framework, research, or simulation-based learning event design. The purpose of this article is to highlight four learning theories that are most commonly integrated into simulation-based learning activities and how they can be specifically and practically applied to pedagogical approaches.

Keywords: simulation, conceptual framework, pedagogy, teaching and learning 


\section{INTRODUCTION}

Simulation-based learning (SBL) has been utilized in healthcare professional education for roughly 60 years. ${ }^{1}$ There is a plethora of research to support the effectiveness and multidimensional benefits of SBL use in educating providers. ${ }^{2-4}$ While it may be a powerful learning tool, simulation demands significant time to design and execute. It often requires specialized space and equipment, trained actors to portray patients, and faculty members to observe and facilitate the debriefing after the event. With the expense that goes into using SBL in a curriculum, it is critical to maximize its effectiveness through purposeful and theoretical design and utilization. ${ }^{5}$

Simulation is a powerful learning tool, but like any other teaching and learning method, proper design and implementation require understanding and incorporating of sound educational learning theory and pedagogical practices. ${ }^{6}$ However, when reviewing much of the published research on SBL, there is limited evidence of integration of educational theory. While articles may reference learning theories in introductions or literature reviews, there is little evidence of these theories being integrated into the conceptual framework, research, or SBL event design. ${ }^{7}$ Instead of looking at SBL as a teaching method, instructors who keep learning as the primary goal of simulation must prioritize the learning process and learning theories when designing and implementing simulation. ${ }^{8}$

When reading healthcare education research, the concepts of learning theory and pedagogy are often used interchangeably; however, there is a significant difference between learning theory and pedagogy that is often overlooked. Learning theories are focused on how learners learn, how they intake, process, and retain new knowledge. Pedagogy is the method and practice by which teachers teach. While these terms are indeed linked, they are not interchangeable.

A review of recent literature on simulation in healthcare education reveals many learning theories that have been applied to SBL activities. Several authors have written specifically about different learning theories that are commonly integrated into SBL activities. ${ }^{8-11}$ The purpose of this article is to highlight four of those theories and present some evidence-based ways they can be practically applied to pedagogical approaches.

\section{BEHAVIORISM}

\section{Theory Overview}

Behaviorism is a learning theory based on the concept that all learning is acquired through conditions. These conditions are based on interactions with the environment and the learner's response to the environmental stimulus. Behaviorism is focused on learning as the overt, observable behavior displayed in response to the environmental stimulus, instead of internal processes liking thinking or emotion. ${ }^{12}$ Learning is equated with "changes in either the form or frequency of observable performance." ${ }^{12}$ Behaviorism strategies are best applied in learning that requires recall of facts, defining concepts, or automatically performing a physical skill or task.

The behaviorism concept of operant conditioning incorporates the impact of consequences on behavior, how learning occurs through reinforcement and punishment. Unlike the premise of classical conditioning theory that directly linked the response to the antecedent stimulus, operant conditioning poses that the response is controlled by the consequences of that response. ${ }^{13}$ When a desirable consequence follows an action or a response, this is likely to create a positive association and this response is more likely to be repeated in the future. Operant conditioning can be considered "learning by doing"13 and supports the use of repetition in learning activities.

The use of reinforcements and punishments, when introduced immediately after a response, drives operant conditioning and alters the response in learners. ${ }^{13}$ Whether applied or withdrawn, reinforcements will strengthen the likelihood of the learner repeating the observed response. Punishments will lessen the learner's likelihood of repeating the observed response, regardless of whether the punishment is applied or negative. In behaviorism, the arrangement of stimuli and consequences in the environment is critical. ${ }^{12}$

\section{Practical Pedagogical Application}

There are multiple concepts and strategies within behaviorism that can be directly applied to SBL activities. First, designing a simulation with a singular focus on a specific psychomotor skill aligns well with behaviorism tenets. ${ }^{6}$ The learning activity should minimize extraneous information or distractions typical of the healthcare setting and just focus on the clear, objective psychomotor task. This allows for the minimization of cognitive demand, ${ }^{6}$ sole attention to be on the individual skill, and direct measurement of the observed behavior to occur. ${ }^{9}$

Second, feedback provided within a SBL activity adheres to the tenets of operant conditioning. Facilitators can reinforce the actions of the learners by providing feedback in the moment. Verbal or tactile feedback, through haptic responses, can be provided through 
simulation technology, such as high-fidelity mannequins. ${ }^{14}$ Delivering this feedback immediately, within the action of the simulation event, allows for actionable changes to the learner's performance to occur. 6,9

Third, incorporating the use of repetition is a critical behaviorism strategy. Providing opportunities for repeated, deliberate practice with a simulation or repeated simulations allows for additional time points of reinforcement to establish stronger associations with actions and behaviors. Repetition allows for ease of recall of the cognitive schema built around a stimulus-response-consequence association. ${ }^{6}$ The repetition and stronger associations also enhance memory formation. ${ }^{9}$

\section{SOCIAL COGNITIVE THEORY Theory Overview}

The introduction of the social cognitive theory (SCT) by Bandura challenged the long-standing dominance of behaviorism in the latter half of the twentieth century. This theory posed that learning is not isolated to an association formed by conditioning, reinforcement, and punishment. Bandura's SCT moved beyond the confines of behaviorism, claiming that learning can occur simply by observing the actions of others. Bandura claimed that human learning occurs in a social environment and is, therefore, extremely context dependent. ${ }^{13}$

Modeling is a critical component of the SCT, as a learner displays changes in behavior, knowledge, or affect from observing one or more models. ${ }^{13}$ Observational learning allows individuals to acquire knowledge, rules, skills, beliefs, and even attitudes through the observation of others. Unlike behaviorism, reinforcement is not necessary for learning to occur with observational learning..$^{13}$ There is diversity in the model that is used for observational learning. It can be with the observation of a live person. It can be symbolic in nature, through movies, podcasts, or social media, or it can be via verbal or written instruction. ${ }^{13}$ Observational learning requires the attention of the learner, retention of information in symbolic form, production of learned behaviors, and motivation from observed consequences of demonstrated behaviors. ${ }^{15}$

Self-efficacy is another essential component in the SCT and is the belief in one's ability to learn or perform the necessary course of action needed to address a situation. ${ }^{13,16}$ Self-efficacy establishes how an individual feels, thinks, and motivates themselves. ${ }^{17}$ The stronger one's self-efficacy, the more likely one would address a difficult task as a challenge to overcome versus a threat to shy away from. Strong self-efficacy leads to aggressive self-set goals, while weak self-efficacy leads to low aspirations and motivation. ${ }^{17}$

\section{Practical Pedagogical Application}

The application of constructs from the SCT can be beneficial throughout multiple aspects of SBL. One primary way that SCT is incorporated into SBL is through team-based simulation events. Designing a simulation event that requires learners to work collaboratively, establish individual and team roles, and communicate effectively provides immense opportunities for observational learning and modeling. Learners may have different strengths and roles to play, such as models for analyzing and synthesizing data, skill performance, or knowledge of how to accomplish complex tasks in a healthcare setting. ${ }^{18}$ Engaging in a community of practice, whether actual or simulated, builds the learners' "knowledge, competence, and personal and professional development." 16

Building the self-efficacy of future healthcare providers is another critical component of the SCT that SBL fulfills. By designing simulation activities that build on classroom concepts, facilitators can in turn engage learners in self-reflection during the event and the debriefing session. An effective debriefing session is key to promoting self-reflection, self-regulation, and self-direction to apply the knowledge and behaviors observed in the simulation to future patient encounters. ${ }^{18}$ Positive feedback from facilitators can promote self-efficacy within student learners. ${ }^{18}$

Bandura states that the most effective way to develop self-efficacy is through mastery experiences, and simulations in healthcare professions education is a perfect application of this tenet. In the health professions, "self-efficacy is a product of mastery, not a source of mastery."16,17 Healthcare providers often work in the middle of controlled chaos, are responsible for the care of multiple patients, interact with numerous other staff, and deal with organizational expectations, which demands a high level of self-efficacy and skill. ${ }^{18}$ Enabling students to engage in simulated communities of practice allows for the development of these skills. The selfefficacy and self-regulation that is a result of SBL aid healthcare students to set goals and self-manage learning behaviors in order to meet those goals. ${ }^{16}$

\section{CONSTRUCTIVISM}

\section{Theory Overview}

Constructivism immerged from the questioning of researchers on assumptions from classical processing theories. Constructivism is an epistemology, not a true theory, and due to the vast definitions of constructivism, there are many different offshoots of the 
core philosophy. Constructivism asserts that individuals construct their own learning based on their individual processing of information. ${ }^{13}$ It is this processing of the information that creates the two most significant contingencies of constructivism, cognitive and social constructivism.

Cognitive constructivism relies heavily on the internal cognitive processing of the individual, with meaning solely constructed by the individual. ${ }^{13}$ Individuals create meaning from their experiences. The mind filters and processes information from the environment to create its own reality, its own knowledge. ${ }^{12}$ Learners do not passively absorb knowledge from the outside world, instead they establish their own understanding based on personal experiences. ${ }^{6,12}$

A primary tent of cognitive constructivism is equilibration, the "biological drive to produce an optimal state of equilibrium." 13 It is this drive for equilibrium that is a key factor in cognitive development. According to constructivists, all learners present with pre-existing knowledge or schemas. When a new experience or information is presented to a learner that conflicts with their pre-existing knowledge, they are presented with a cognitive dilemma and desire to resolve it. ${ }^{6}$ The learner can use either assimilation or accommodation to resolve the conflict. With assimilation, the learner takes in new information and integrates it into pre-existing knowledge. With accommodation, the learner uses the new information to revise or change existing knowledge to make it consistent with the external reality.

Social constructivism emphasizes the influence of society and culture on the construction of knowledge. ${ }^{13}$ While learners still construct their own knowledge, cognitive development is mediated by individuals that interact with the learner. This cognitive development is highly contextual, and therefore the learning environment should be as authentic as possible.

A key concept in social constructivism is the zone of proximal development, which is considered the gap between what learners are capable of doing independently and what they can do with guidance or collaboration. The incorporation of instructional scaffolding can support learners as they master concepts that might not otherwise be possible, facilitating increased learner confidence and competence. ${ }^{13}$ Concepts like the zone of proximal development and instructional scaffolding allow students to perform more challenging tasks, potentially advancing their learning faster.

\section{Practical Pedagogical Application}

Simulation-based learning activities provide an excellent opportunity to engage constructivism tenets towards student learning. However, attention to simulation design and implantation is key to ensuring an ideal learning environment. Since constructivism is founded on the concept that learners form their own learning, a simulation facilitator must prepare for students' different experiences and perceptions of the same simulation event. ${ }^{14}$ The debriefing aid students in seeing how and why they performed differently than others in the same simulation. ${ }^{14}$

The typical design of a scenario, with a pre-briefing, event, and debriefing, provides a framework that supports a constructivism approach. A well-designed and implemented simulation event allows learners to independently establish a hypothesis, typically based on the details provided in the pre-briefing and upon entering the simulation event. ${ }^{6}$ The scenario must be well-written based on the students' curriculum and current knowledge base so that it presents challenges to their skills and critical thinking. This creates the opportunity for a cognitive conflict when a component of the simulation challenges a student's pre-existing knowledge. An attentive debriefing facilitator can help the student re-configure their existing knowledge based on how they think and act within the simulation.

Incorporating the zone of proximal development and scaffolding concepts into SBL activities requires diligent planning and support throughout the event. Simulation events can be designed to push learners to the edge of their zone of proximal development. However, caution must be taken that the scenario is not too demanding. It could be more destructive in nature and learning opportunities would be lost. ${ }^{19}$ Adding in scaffolding, such as formative task checklists or floating faculty for questions and feedback, can provide support and improve the construction of knowledge in the moment. ${ }^{20}$ Utilizing team-based SBL activities enables peer feedback and scaffolding to advance learner's knowledge construction. ${ }^{20}$

The challenge with a constructivist approach to simulation design is that all learners will not necessarily experience the same learning based on the event. ${ }^{6}$ Every SBL activity is written with specific learning objectives to be accomplished, and on the surface, the constructivist approach can appear to be a potential barrier to achieving them. While a scenario is designed to direct learners towards these specific learning objectives, the learners can still independently and critically think, establishing their own learning and solutions to the presented situation. ${ }^{6}$ It is then critical that the debriefing facilitators guide the students to frame their own learning within the event's learning objectives.

5. 


\section{EXPERIENTIAL LEARNING THEORY \\ Theory Overview}

Experiential learning theory was established in the 1980s by David Kolb and incorporates many constructivist concepts. According

to Kolb, learning occurs through the transformation of experience. ${ }^{21}$ The experiential learning cycle consists of four phases:

1. Concrete Experience - This is the experience of which the learner is part.

2. Reflective Observation - The learner reflects on the experience, the event's details, and their personal response to it.

3. Abstract Conceptualization - This phase is where the learner can think logically on the experience, focusing their observations into new thoughts or approaches for a future similar situation.

4. Active Experimentation - This phase allows for the testing of these new ideas in a new experience.

Each of these phases is mutually supportive and feeds into others. Learning from a single experience does not occur in one specific phase of this cycle but requires the entire cycle in order to be effective. Learning across time does not occur in individual cycles, but as a spiral, with each concrete experience and cycle building off the ones before it. ${ }^{21}$

There are six central tenets of experiential learning.22 First, learning is not an outcome but a process. Ideas and thoughts are formed and re-formed based on experiences. Second, all learning is relearning. An experience will bring up existing beliefs and theories to be questioned and tested and then allows for new ideas to be integrated and the old belief systems and theories are refined. Third, effective learners must balance the opposing modes of adapting to the world, the conflict between reflection and action, and the conflict between thinking and feeling. Learners must be able to balance the demands of all four modes in order to learn successfully. Fourth, learning is a holistic process of adapting based on experiences. This process requires all aspects of a person's processing, feeling, thinking, perceiving, and behaving. Fifth, the learner and the environment are both changed by the learning process. There is a reciprocal influence that each factor has over the other. Sixth, learning is the process of creating knowledge. New knowledge is formed when old knowledge comes into contact or conflict with a new experience.

\section{Practical Pedagogical Application}

Experiential learning theory is the most used theory with SBL. ${ }^{23}$ However, in order for a SBL activity to adhere to the experiential learning theory and cycle, it must be designed to meet all phases of the cycle. The simulation event itself is the concrete experience, which is the catalyst for learning. This experience allows the learner to identify gaps in their knowledge. ${ }^{11}$ The simulation should be challenging enough to stress the learner, but not so much as to impede learning. ${ }^{11}$ The post-event debriefing encompasses the reflective observation phase, where the learners work to make sense of what occurred during the event. Debriefing facilitators can provide an objective view of what occurred in the event, to which the learners can compare their own perception of the event. ${ }^{11}$ The facilitators can also engage the learner's reflective thoughts with probing, open-ended questions. The expectation is that the learners will change their pre-existing mental model. In other words, for learning to occur, the learners must reflect on their behaviors and rationale within the event. ${ }^{11}$

Once the learners have made their own sense of the event, the debriefing facilitator must then take the opportunity to shift the discussion into the abstract conceptualization phase. At this point, the learners consider the relevance of the experience and what, if anything, they could do differently in the future. ${ }^{24}$ Through discussion and facilitation by the debriefer, the learners shape a new model of thoughts and ideas, incorporating outside resources and thoughts if necessary. ${ }^{11}$ The last phase is active experimentation, where the learners have the opportunity to put these new thoughts and ideas to practice. Ideally, this could take place in a new simulation. However, if there is too much time between simulation events, the learners could revert to their old mental model. ${ }^{11}$ Simulation planners could consider having a simulation-debriefing-repeat simulation event model, allowing the learners to go back into the simulation to help cement the new learning from the debriefing session.

Considering Kolb's experiential learning theory as a whole, the six central tenets mentioned previously align with SBL, whether a high-fidelity simulation with a mannequin, with a patient actor, or with a computer-based program. ${ }^{20}$ Kolb's remarks that characterize the learning cycle as a spiral also directly correlate with SBL. This supports the concept that SBL activities in healthcare professional education need to build upon one another throughout a curriculum and even into professional learning.

\section{CONCLUSION}

A broad array of educational learning theories can be applied to SBL activities in healthcare education. This article has only highlighted four of them, behaviorism, social cognitive theory, constructivism, and experiential learning. Additionally, this article has tied practical pedagogical applications of these theories for incorporation into SBL, along with supporting evidence from the literature. Each of these learning theories on their own can provide a solid framework for SBL activities. However, more than one theory is likely applied to any given SBL event, improving the effectiveness of the activity. Readers are challenged to investigate different theoretical frameworks and consider how simulations can be more deliberately designed with specific frameworks in mind. 


\section{REFERENCES}

1. Hall K, Tori K. Best practice recommendations for debriefing in simulation-based education for Australian undergraduate nursing students: An integrative review. Clin Simul Nurs. 2017;13(1):39-50. doi:10.1016/j.ecns.2016.10.006

2. Sabus C, Macauley K. Simulation in physical therapy education and practice: Opportunities and evidence-based instruction to achieve meaningful learning outcomes. J Phys Ther Educ. 2017;30(1):3-13. doi:10.1097/00001416201630010-00002

3. Brydges R, Hatala R, Zendejas B, Erwin PJ, Cook DA. Linking simulation-based educational assessments and patientrelated outcomes. Acad Med. 2015;90(2):246-256. doi:10.1097/acm.0000000000000549

4. Singh P, Aggarwal R, Pucher PH, et al. An immersive "simulation week" enhances clinical performance of incoming surgical interns improved performance persists at 6 months follow-up. Surg (United States). 2015;157(3):432-443. doi:10.1016/j.surg.2014.09.024

5. Yeung E, Dubrowski A, Carnahan H. Simulation-augmented education in the rehabilitation professions : A scoping review. Int J Ther Rehabil. 2013;20(5):228-236. doi:10.12968/ijtr.2013.20.5.228

6. Parker BC, Myrick F. A critical examination of high-fidelity human patient simulation within the context of nursing pedagogy. Nurse Educ Today. 2009;29(3):322-329. doi:10.1016/j.nedt.2008.10.012

7. Shepherd I, Burton T. A conceptual framework for simulation in healthcare education - The need. Nurse Educ Today. 2019;76(August):21-25. doi:10.1016/j.nedt.2019.01.033

8. Kaakinen J, Arwood E. Systematic review of nursing simulation literature for use of learning theory. Int J Nurs Educ Scholarsh. 2009;6(1). doi:10.2202/1548-923X.1688

9. McGaghie WC, Harris IB. Learning theory foundations of simulation-based mastery learning. Simul Healthc. 2018;13(3S Suppl 1):S15-S20. doi:10.1097/SIH.0000000000000279

10. Rutherford-Hemming T. Simulation methodology in nursing education and Adult Learning Theory. Adult Learn. 2012;23(3):129-137. doi:10.1177/1045159512452848

11. Zigmont JJ, Kappus LJ, Sudikoff SN. Theoretical foundations of learning through simulation. Semin Perinatol. 2011;35(2):47-51. doi:10.1053/j.semperi.2011.01.002

12. Ertmer PA, Newby TJ. Behaviorism, Cognitivism, Constructivism: Comparing critical features from an instructional design perspective. Perform Improv Q. 2013;26:43-71. doi:10.1002/piq.21143

13. Schunk D. Learning Theories: An Educational Perspective. 8th ed. Pearson; 2020.

14. Dieckmann P, Ringsted C. Pedagogy in simulation-based training in healthcare. In: Forrest K, McKimm J, Edgar S, eds. Essential Simulation in Clinical Education. West Sussex: Wiley-Blackwell; 2013:43-58. doi:10.1002/9781118748039

15. Bandura A. Social Learning Theory. New York: General Learning Press; 1971.

16. McGaghie WC, Issenberg SB, Barsuk JH, Wayne DB. A critical review of simulation-based mastery learning with translational outcomes. Med Educ. 2014;48(4):375-385. doi:10.1111/medu.12391

17. Bandura A. Self-efficacy. In: Ramachaudran VS, ed. Encyclopedia of Human Behavior. New York; 1994:77-81.

18. Burke H, Mancuso L. Social cognitive theory, metacognition, and simulation learning in nursing education. J Nurs Educ. 2012;51(10):543-548. doi:10.3928/01484834-20120820-02

19. Groot F, Jonker G, Rinia M, Ten Cate O, Hoff RG. Simulation at the frontier of the zone of proximal development: A test in acute care for inexperienced learners. Acad Med. 2020;95(7):1098-1105. doi:10.1097/ACM.0000000000003265

20. Becker LR, Hermosura BA. Simulation education theory. In: Deering S, Auguste T, Goffman D, eds. Comprehensive Healthcare Simulation: Obstetrics and Gynocology. Comprehensive Healthcare Simulation. Springer; 2019:11-24. doi:10.1016/B978-0-12-420123-1.00011-3

21. Kolb D. Experiental Learning: Experience as the Source of Learning and Development. 2nd ed. Upper Saddle River: Pearson; 2014.

22. Kolb AY, Kolb DA. Learning styes and learning spaces: A review of multidisciplnary application of experiental learning theory in higher education. In: Sims RR, Sims SJ, eds. Learning Styles and Learning: A Key to Meeting the Accountability Demands in Education. New York: Nova Science Publishers; 2006:45-91.

23. Keskitalo T. Developing a pedagogical model for simulation-based healthcare education. 2015.

24. Poore JA, Cullen DL, Schaar GL. Simulation-based interprofessional education guided by Kolb's experiential learning theory. Clin Simul Nurs. 2014;10(5):e241-e247. doi:10.1016/j.ecns.2014.01.004 